\title{
TOTAL NUMBER: A BRIEF REVIEW OF ITS IMPORTANCE AND ITS USE IN ASSESSING CEREBELLAR DAMAGE IN THE RAT FOLLOWING EARLY POSTNATAL ALCOHOL EXPOSURE
}

\author{
RUTH MA NAPPER \\ Department of Anatomy and Structural Biology, School of Medical Sciences, University of Otago, Dunedin, \\ New Zealand \\ (Accepted February 14, 2000)
}

\begin{abstract}
Knowledge of the total number of structural components that make up the various neural networks within the central nervous system is fundamental to our understanding of its normal function and of dysfunction that may accompany injury and disease. This paper briefly reviews the methodology currently used to estimate number and discusses the importance of unbiased estimates of total number in determining changes in brain structure that may underlie dysfunction. An example from the olfactory bulb is used to demonstrate the potential invalidity of using estimates of total number of objects per single section. Exposure to alcohol during the early postnatal period results in motor dysfunction in adult rats. This paper presents data on the extent and magnitude of cell loss within the cerebellar network of the rat following alcohol exposure during postnatal days 4 to 9 . High transient blood alcohol concentrations result in a Purkinje cell of $27 \%$ across the entire cerebellum but with regional variabiltiy, vermal lobule $\mathrm{X}$ has a $43 \%$ Purkinje cell deficit. This alcohol regimen also results in a neuronal loss of $28 \%$ and $25 \%$ within the deep cerebellar nucleus and inferior olivary nucleus respectively. Consistency of overall neuronal loss across diverse neuronal populations within the cerebellar network is discussed in the context of the maintenance of cerebellar connectivity.
\end{abstract}

Keywords: cerebellar network, cerebellum, fetal alcohol syndrome, total number.

\section{INTRODUCTION}

Neurons, non neuronal cells, synapses and receptors are a few of the structural components of the central nervous system that are fundamental to the integration and transfer of information within the neural networks that comprise the nervous system. Their number must be important in defining the functional capacity of the neural system they are a part of. Knowledge of the total number of components e.g. neurons and synapses, that form the different parts of a neural network is important in understanding the normal function of brain regions (Liley and Wright, 1994). It is also important in assisting our understanding of how function may change during development (Tolcos and Rees, 1997), as a result of many disease processes or insults (Goodlett and Lundahl, 1996), during ageing and as a result of a novel environmental experience (Kempermann et al., 1997). Animal models are widely used to study these phenomenon and to relate the changes in function and structure, to specific disease processes or pathology that is seen in the human population (Goodlett and Lundahl, 1996; Sowell et al., 1996). In the past much of the data, either from animal models or the human population, that was available and used to make conclusions about disease processes or the structural basis of function and dysfunction was not reliable, in that it was produced in a biased way or was a measure of density (Swaab and Uylings, 1987). With the description of the disector method (Sterio, 1984) and other direct counting methods (Howard et al., 1985), human and animal model data, in the form of unbiased estimates of total number, is becoming increasingly available (e.g. Braendgaard and Gundersen, 1990; Pakkenberg and Gundersen, 1988; Aika et al., 1993; West, 1993; West et al., 1996). This quantitative information is very important in assessing the robustness of animal models and the discrepancies between animal models and human data (Harding et al., 1997).

We have used unbiased stereological methods to assess the magnitude and extent of the cell and synaptic loss that occurs in the cerebellum of the rat following exposure to alcohol during the early neonatal period. This paper will discuss the importance of using unbiased counting methods to obtain total number and present data that illustrates the value of estimates of total 
number when assessing alcohol induced brain damage. We suggest that it is advantageous to estimate the total number of neurons and synapses within a number of functionally related cell populations of the cerebellar network, as a way of understanding the structural changes that may underlie the motor deficits seen in adult rats with alcohol-induced cerebellar damage.

\section{DETERMINATION OF TOTAL NUMBER}

The large numbers of neurons comprising the central nervous system makes the counting all neurons by serial section analysis an impractical way to obtain total number, even for a relatively small brain region and essentially impossible for a count of synapses (Coggeshall, 1992). However estimates or approximations taken from samples can provide very useful data although in the past due to the methods available for use, this has not always been the case (see West, 1999).

The first stage in estimating total number is the estimation of total number per unit volume, density, in a sample of tissue, generally a section of some known thickness. This density measure is not of any real use (Oorschot, 1994) but can be converted to total number, typically by one of two approaches. The first is a two stage process and involves estimating the volume of the structure within which the particles of interest are found, namely the reference volume or Vref, and combining the density, $\mathrm{Nv}$, with this to obtain the total number of particles (e.g. Geinisman et al., 1996; Pakkenberg and Gundersen, 1988). The second method is a more direct method known as the fractionator method and involves counting the number of particles within a known fraction of the structure of interest (e.g. Mouton et al., 1994; Pakkenberg and Gundersen, 1997; West et al., 1991). The density, that is directly estimated by counting in the tissue sample, is converted to total number by multiplying it by the inverse of the fraction of the tissue sampled. Both of these approaches produce estimates of total number. Over the years, and still today, a number of different methods have been used to count the particles, whether they are neurons, synapses or another discrete identifiable component of a cell, to obtain the estimate of density. There has been a lot of debate about which of the various counting methods is the most appropriate to use (Coggeshall and Lekan, 1996; Mayhew, 1992). This has centred on whether the stereological counting method is an assumption based method or a design based method.

Assumption based methods count profiles in a thin section and assume that there is a known relationship between the profiles seen in the section and the parent particles in the object from which the section has been cut (Weibel, 1980). There is however no simple relationship between the number of profiles in a single section and the number of particles in the volume the section was taken from. Assumptions based on the geometry of the particle are used to establish a relationship between profile counts and particle counts. Two assumptions most commonly included in these methods concern the fact that the probability that any particle will be hit by a plane of section and thus occur in the thin section, depends on the height of the particle in a direction normal to the plane of section and on the thickness of the section (Abercrombie, 1946). Other assumptions that may be included concern the size of the smallest observable particles to account for 'lost caps', particles that are so small they are essentially lost from the section and 'overprojection' and 'overlap' where the appearance of the particle is distorted due to the thickness of the section (see Cruz-Orive, 1983). The values attributed to these factors and incorporated in assumption based methods can be measured but if the values used are not the true values the estimate of number derived using these values will be biased. The extent of this bias will be unknown as the difference between the true and estimated values will not be known unless a serial section analysis is carried out to correlate the data obtained in the two different ways (Coggeshall, 1992). Particle geometry may change as a result of many experimental manipulations or during tissue processing in a variable manner making it necessary to carry out a correlative study in parallel with each assumption based analysis.

Design based counting methods count particles directly in a defined volume of space (see West, 1999). Direct counting can use disectors (Sterio, 1984) or other 3 dimensional counting probes (Howard et al., 1985). Most importantly they do not directly use knowledge of the size, shape or orientation of the particles in space. The original disector method, now commonly referred to as the physical disector (Sterio, 1984), uses parallel section planes a known distance apart. Particles, identified by a unique feature, are counted when they appear within an unbiased counting frame, placed on one of the section planes (the reference plane), but are not present in the other section plane (the lookup plane). (For a full description of this method see Sterio, 1984.) That each particle has an uppermost point, a fact which is true of all particles, is the only information needed about the particle as long as all profiles belonging to a particle can be identified (see Gundersen, 1986; Mayhew and Gundersen, 1996). The physical disector has led to the development of the optical disector that uses optical planes as the disectors, within a single thick section which in turn has led to the development of the optical fractionator method in which the optical disector 
is used in a known fraction of the tissue. These methods have been described in detail by Gundersen (1986), West et al., (1991) and Mayhew and Gundersen (1996).

These developments increase the efficiency of the use of the disector method, but it is the direct counting of particles in the disector method that is fundamental to the design based method. The disector method produces a density which although unbiased, is not of great value because cell densities do not equate to cell number (Navaroo et al., 1996). Oorschot (1994) presents a thorough discussion of the problems of using density as a measure. Use of the disector method or other direct counting methods to obtain an unbiased estimate of total number would ensure that published quantitative data became a reliable resource.

\section{SINGLE SECTION VERSUS TOTAL NUMBER}

The disector method or other direct counting methods are now increasingly used but assumption based methods have been widely used in the past to obtain data that underlies much of our neuroscience knowledge whether presented as density measures or total number. Also commonly used as a way of presenting quantitative information is total number within a single section taken from a known position within a structure. Whether assumption or design based methods are used to obtain the estimate of total number per section this is not of great value. A change in total number in a single section may not equate proportionately to the change occurring in the entire structure.

Total number per single section was used by Bonthius and West, (1991a) in their investigation of the short- and long-term effects of postnatal alcohol exposure on the structure of the olfactory bulb. Animals were exposed to alcohol from postnatal day 4 (PN4) to PN10 and at either 10 or 90 days of age the animals were killed and the olfactory bulb investigated to determine the extent of alcohol-induced cell loss. All mitral cell fragments with a clearly discernible nuclear membrane were counted in a single $2 \mu \mathrm{m}$ thick coronal section from the midpoint along the length of the right olfactory bulb. Granule cell fragments, with clearly discernible nuclear membranes, were counted in a sample at selected sites within the internal granule cell layer and combined with the area of the internal granular layer to give an estimate of the total number of granule cells in the section (see Bonthius and West, 1991a; for detailed methodology). The distribution of nuclear fragment diameter was estimated from random samples of the mitral and granule cell populations and was found not to change between experimental groups so was not considered in the conversion of profile counts to particle counts. They found that mitral cell number was significantly less following postnatal binge alcohol exposure at both 10 and 90 days of age but granule cell number was significantly reduced at only PN10. By PN90 the number of granule cells in the alcohol exposed animals did not differ significantly from the controls thus indicating that some degree of recovery had occurred in the granule cell population following cessation of the alcohol exposure (see Table 1).

The authors did emphasise that there was a trend in the data towards a deficit in granule cell number at 90 days of age and that and a more complete analysis of cell numbers over the entire rostro-caudal axis of the olfactory bulb may have detected a permanent effect of alcohol on granule cell number.

Bonthius et al. (1992) repeated this study using unbiased stereological methods to determine the total number of mitral cells and granule cells in the olfactory bulb after an identical regime of neonatal alcohol exposure (see Bonthius et al., 1992 for methodological details). The number of mitral cells was significantly reduced in the alcohol exposed animals at both 10 and 115 days of age, with a $37 \%$ deficit at PN10 and 27\% deficit at PN115. The number of granule cells was also significantly reduced in the alcohol exposed animals at 10 and 115 days of age, in contrast to the earlier study (Bonthius and West, 1991) (see Table 2). The magnitude of the granule cell deficit was a $33 \%$ at PN10 and $19 \%$ at PN115 but this difference was not statistically significant different. Interestingly the difference in magnitude of the cell loss in the two populations at PN115 does result in a significant difference $(p<0.01)$ in the ratio of granule cells to mitral cells in the alcohol exposed animals $(130.4 \pm 5.7$, mean sd) compared to both control groups $(117.3 \pm 3.9$ and $118.7 \pm 5.6$ for the suckle and gastrostomy controls respectively).

The alcohol-induced deficits in both cell populations were mainly due to reductions in the volumes of the layers containing the cells rather than reductions in packing densities (see Bonthius et al., 1992) and hence could not be detected to the true extent in a single section analysis. 
Table 1. Total number of mitral and granule cells in a single $2 \mu \mathrm{m}$ coronal section of the olfactory bulb in 10 day old and 90 day old rats ${ }^{1}$.

\begin{tabular}{lllll}
\hline & 10 day old rats & & 90 day old rats & \\
\hline Treatment group & $\begin{array}{l}\text { Mitral cells } \\
\text { in single section }\end{array}$ & $\begin{array}{l}\text { Granule cells } \\
\text { in single section }\end{array}$ & $\begin{array}{l}\text { Mitral cells } \\
\text { in single section }\end{array}$ & $\begin{array}{l}\text { Granule cells } \\
\text { in single section }\end{array}$ \\
\hline SC & $214 \pm 6$ & $7419 \pm 343$ & $156 \pm 7$ & $8905 \pm 380$ \\
GC & $220 \pm 8$ & $7095 \pm 285$ & $152 \pm 5$ & $8429 \pm 323$ \\
$10.2 \%$ & $153 \pm 7 *$ & $5095 \pm 343 *$ & $116 \pm 7 *$ & $8000 \pm 390$ \\
\hline
\end{tabular}

${ }^{1}$ All measures represent means \pm sem.

*Significantly different from both control groups $(\mathrm{P}<0.01)$

Modified from Bonthius and West, 1991, with permission from DJ Bonthius.

Table 2. Total number of mitral and granule cells in the olfactory bulb in 10 day old and 115 day old rats ${ }^{1}$.

\begin{tabular}{lllll}
\hline Treatment group & $\begin{array}{l}\text { 10 day old rats } \\
\left(\times 10^{4}\right)\end{array}$ & $\begin{array}{l}\text { N - Granule cells } \\
\left(\times 10^{6}\right)\end{array}$ & $\begin{array}{l}\text { N - Mitral cells } \\
\left(\times 10^{4}\right)\end{array}$ & $\begin{array}{l}\text { N - Granule cells } \\
\left(\times 10^{6}\right)\end{array}$ \\
\hline SC & $5.30 \pm 0.27$ & $2.20 \pm 0.14$ & $4.33 \pm 0.24$ & $5.06 \pm 0.23$ \\
GC & $5.22 \pm 0.18$ & $2.13 \pm 0.10$ & $4.30 \pm 0.15$ & $5.12 \pm 0.20$ \\
$10.2 \%$ & $3.30 \pm 0.26 *$ & $1.43 \pm 0.12 *$ & $3.17 \pm 0.18 *$ & $4.14 \pm 0.25 *$ \\
\hline
\end{tabular}

${ }^{1}$ All measures represent means \pm sem.

*Significantly different from both control groups $(\mathrm{P}<0.01)$

Modified from Bonthius et al., 1992, with permission.

The original finding of a return to normal numbers in the granule cell population despite mitral cell loss was a very interesting finding and most probably would have had consequences for the function of the olfactory bulb due to the reciprocal synaptic connections between the two populations. The use of unbiased stereological methods has however shown that the mitral and granule cells of the olfactory bulb both show a permanent deficit following postnatal alcohol exposure. Despite the increase in granule cell to mitral cell ration following alcohol-induced cell loss the deficit in granule cells may be an attempt to maintain the normal quantitative relationship between these two populations in the olfactory bulb. It is also interesting to note that unbiased stereological methods have not only shown a previously undetected loss of granule cells but have provided quantitative information on the normal development of the rat olfactory bulb. This information is important comparative data for earlier studies and for use in future work.

Quantifying changes in the number of structures in a region of the brain as a result of disease or an insult to the brain, is a very important part in understanding the dysfunction that accompanies brain damage. Brain dysfunction resultant from maternal alcohol consumption during gestation is considered to be a leading cause of mental deficiency in the Western world (Abel, 1995). Studies using animals models have provided unequivocal evidence that alcohol is teratogenic (Chernoff, 1977; Sulik et al., 1984) and have reported cell loss and structural changes in a number of brain regions (e.g. West 1987; Miller and Potempa, 1990; Miller and AlGhoul, 1993; Goodlett and Lundahl, 1996). Much of this data predates the use of unbiased stereological methods and is therefore of questionable value as we try to determine the link between structure and function in the alcohol damaged brain.

During both normal development and as a result of alcohol-induced damage there may be many changes in the brain, such as changes in the size of a brain region and changes in the size and shape of cells and synapses. Such potential changes highlight the danger of using assumption based methods and reinforce the need to use design based counting methods.

The cerebellum is particularly vulnerable to alcohol damage especially during the early postnatal period in the rat (Bonthius and West, 1990; Bonthius and West, 1991b; Hamre and West, 1993; Marcussen et al., 1994; Goodlett and Lundahl, 1996) which roughly corresponds to the human third trimester. Work by Bonthius and West (1991b) has shown that there is a distinct lobular sensitivity to the neurotoxic effects of alcohol with some lobules of the cerebellum showing very severe loss of both Purkinje cells and granule cells and other lobules no significant loss. More recently work by Goodlett and Lundahl (1996) using the optical fractionator method, 
has shown that binge alcohol exposure in the neonatal rat that did not cause Purkinje cell loss did result in impaired motor performance on a parallel bar traversal test on PN 42-44. Purkinje cell loss was assessed across the entire cerebellar cortex which, based on the work of Bonthius and West (1991) may have obscured cell loss in specific cerebellar lobules whose function is critical for the motor skills involved in parallel bar traversal. These findings suggest that unbiased stereological methods may be important in assessing the true extent of cerebellar damage in the rat following neonatal alcohol exposure.

\section{CHANGES IN TOTAL NUMBER IN THE CEREBELLUM FOLLOWING ALCOHOL EXPOSURE FROM POSTNATAL DAY 4 TO 10}

\section{Cerebellar regions}

Significant cell loss had previously gone undetected when single section analysis was used (Bonthius and West, 1991a) suggesting the possibility of an undetected cell loss in the cerebellum following exposure to low BACs and the importance of using unbiased stereological methods to detect changes in total cell number. The total number of Purkinje cells was determined in the entire cerebellum following postnatal alcohol exposure to high transient BACs and low continually elevated BACs. The cerebellar cortex shows considerable regional vulnerability to the neurotoxic effect of alcohol when alcohol is delivered from postnatal day 4 (PN4) to PN9 in a binge regime that achieves transient but high blood alcohol concentrations (BACs) (Bonthius and West, 1991b). Cell loss on a lobular basis has not been seen with low but continually elevated BACs where analysis was carried out on a single midvermal section (Bonthius and West, 1991b) Cerebellar lobules in which the Purkinje cells mature early in development are more susceptible to cell loss following postnatal alcohol exposure than Purkinje cells in later maturing lobules (Bauer-Moffett and Altman, 1977; Bonthius and West, 1990, 1991b). It is possible that the early maturing lobules may show cell loss with lower BACs if more sensitive methods of assessing the cell loss are used. The floccular-parafloccular region (FPF) of the cerebellum may be particularly sensitive to alcohol-induced damage because the dendritic outgrowth of the Purkinje cells in the FPF, as demonstrated by MAP-2 immunocytochemistry, shows that the Purkinje cells in this region mature early (unpublished observations) suggesting that it may have a similar alcohol sensitivity as the early maturing vermal lobules. The total number of both the Purkinje cells and granule cells was determined because the two cell populations are at very different stages of development during the period of alcohol exposure and it is not known if alcohol interferes with neurogenesis or with the differentiation and growth of neurons. The FPF, as an early maturing region of the cerebellum was expected to show a deficit in Purkinje cell and granule cell number but it is possible that there would also be an effect on the synaptic relationship between the two cell populations that may parallel the cell loss or attempt to compensate for it. To assess this the total number of granule cell synapses on an individual Purkinje cell in the FPF, the parallel fibre Purkinje cell dendritic spine synapses, was estimated using unbiased stereological methods.

Goodlett and Lundahl (1996) have shown that there are significant motor deficits in mature rats following binge alcohol exposure during the neonatal period, without Purkinje cell loss. With evidence for significant cell loss in some cerebellar lobules and no change in others (Bonthius and West, 1991b) it is possible that the result reported by Goodlett and Lundahl (1996) was due to a significant loss of Purkinje cells in a single lobule that is essential for motor performance on the parallel test. This loss in a single lobule would be masked by the lack of cell loss in other lobules when total Purkinje cell number in the entire cerebellar cortex was determined. Vermal lobule $\mathrm{X}$ and the paramedian lobule of the cerebellar hemisphere were assessed following binge postnatal alcohol exposure that resulted in BACs of around $278 \mathrm{mg} / \mathrm{dl}$ to determine to what extent the magnitude of cell loss varied between lobules and compared to loss across the entire cerebellum. Lobule $\mathrm{X}$ was selected as an alcohol sensitive region, having shown a Purkinje cell loss of around $34 \%$ in a single midvermal section (Bonthius and West, 1991b). The paramedian lobule was selected because it is involved in head, forelimb and to some degree hind limb movements related to various aspects of body positioning and locomotion. Rats exposed to this high BAC regimen show significantly reduced motor performance on a set of specific motor skills, skills that require function of the PML (Klintsova et al., 1998). Also, as the PML is continuous with vermal lobule VII, which from Bonthius and West's work $(1990,1991 b)$ is considered to be relatively resistant to the neurotoxic effects of alcohol, possibly has a subpopulation of Purkinje cells more resistant to the neurotoxic effects of alcohol.

The sole output from the cerebellar cortex is via the axons of the Purkinje cells, a large proportion of which synapse on the neurons of the deep cerebellar nucleus (DCN). Within the DCN around $90 \%$ of all somatic and $50 \%$ of all dendritic synapses are formed by Purkinje cell axons. The inferior olive is another region of prime importance in the cerebellar complex, as the sole source of climbing fibre afferents to the Purkinje cells (Ito, 1984). Unbiased stereological methods were used to determine if alcohol induced Purkinje cell loss or alcohol neurotoxicity directly had an effect on the number of 
neurons in these two nuclear complexes.

\section{METHODS}

One group of rat pups, the suckle control rats, (SC group) was reared normally by dams. The other groups were artificially reared. On postnatal day four (PN4, gestational day 26), a gastrostomy feeding tube was implanted in the stomach of each rat pup assigned to an artificially reared group. Throughout the artificial rearing period the rat pups were fed a milk solution at regular intervals as described in detail elsewhere (West et al., 1984; Napper and West, 1995). Three artificially reared groups were exposed to alcohol. Two groups received a daily alcohol dose of $4.5 \mathrm{~g} / \mathrm{kg}$, administered either as a $5.1 \%(\mathrm{v} / \mathrm{v})$ solution in 4 consecutive daily feedings $(5.1 \%$ group) or as a $10.2 \%(\mathrm{v} / \mathrm{v})$ solution in 2 consecutive daily feedings $(10.2 \%$ group $)$. The remaining feedings were alcohol-free, i.e. milk formula alone. The third group received $6.6 \mathrm{~g} / \mathrm{kg} / \mathrm{day}$ of alcohol as a $2.5 \%(\mathrm{v} / \mathrm{v})$ solution in each of the 12 daily feedings ( $2.5 \%$ group). An additional artificially reared group (gastrostomy control group, GC group) received an alcohol-free formula isocaloric to the $4.5 \mathrm{~g} / \mathrm{kg}$ alcoholcontaining diet in 4 consecutive daily feedings (matched to the $5.1 \%$ group) with the remaining 8 feedings consisting of milk formula alone. Pups were either killed on PN10 or artificially reared on milk solution alone on days PN10 and PN11 when they were fostered to normal dams and reared under standard conditions until PN115 when they were killed for study. Blood alcohol concentrations (BACs) were determined twice from $20 \mu \mathrm{l}$ tail blood samples for each rat pup as described in detail previously (Napper and West, 1995).

After postfixation in $10 \%$ neutral buffered formalin for at least 2 weeks the tissue of interest region was blocked and processed for embedding in glycolmethacrylate (Technovit 7100, Kulzer \& Co.). (Details can be found in Napper and West, 1995.) The blocks were serially sectioned at $40 \mu \mathrm{m}$ on a Reichert-Jung rotary microtome using glass knives and a random systematic series of sections was saved. The sections were mounted onto glass slides, stained with Geimsa Cresyl Violet stain coded and were analysed blind.

Unbiased stereological methods were used to determine the total number of neurons in a range of cerebellar regions and associated nuclei. The volume of the region containing each population of neurons, the 'reference volume' (Vref), was determined using Cavalieri's principle (Gundersen et al., 1988a) and the density (Nv) of neurons within this volume was determined using the optical disector method (Gundersen, 1986). The total number of neurons for each population was calculated as the product of the reference volume containing the neuronal population and the density of neurons within that volume. $\mathrm{N}=\operatorname{Vref} \mathrm{x} \mathrm{N}$.

The disector method was used on pairs of electron micrographs taken form the middle third of the molecular layer to determine the density of parallel fibre to Purkinje cell spine synapses in the flocculus paraflocculus region and paramedian lobule of the cerebellar cortex. Purkinje cell density was determined in $1.5 \mu \mathrm{m}$ sections of the same material using the physical disector method and cell and synapse densities were combined to give an unbiased estimate of the total number of parallel fibre synapses on an individual Purkinje cell. Only the high BAC binge group (10.2\% group) was used in synapse estimations.

All statistical analyses were performed using the mainframe SPSS statistical package. Reference volume, cell density, synapse density, total cell number, total synapse number and cell population to cell population ratios were analysed with one-way analysis of variance (ANOVA). Posthoc pairwise comparison of group means was carried out using both Scheffe tests and the Neuman-Keuls test when treatments were significantly different according to the ANOVA. (P values relate to the use of the Neuman-Keuls test unless stated otherwise.) For data obtained from systematically placed sections within an individual subject the $\mathrm{CE}$ of the estimate of the number of objects sampled ( $\Sigma$ Q-) was calculated according to the procedures described by West and Gundersen (1990). The CE was used to ensure the efficiency of the sampling design and the reliability of the estimates and values are not included.

\section{RESULTS AND DISCUSSION}

The delivery of alcohol under the different paradigms resulted in different patterns of blood alcohol concentration (BAC). The two groups receiving alcohol ( $4.5 \mathrm{~g} / \mathrm{kg} /$ day) concentrated into two (10.2\% group) or four (5.1\% group) consecutive feedings had peak BACs $(\mathrm{mg} / \mathrm{dl})$ of $278 \pm 22($ mean $\pm \mathrm{sd})$ and $189 \pm 19$ and trough BACS of $6.8 \pm 7.4$ and $5.9 \pm 7.4$ respectively. The group receiving the higher daily dose $(6.6 \mathrm{~g} / \mathrm{kg} /$ day $)$ in uniform amounts throughout the day (2.5\% group) had peak and trough BACs of $34 \pm 15$ and $20 \pm 9$, respectively. The peak BACs were significantly different $(p<0.01)$ among the three groups.

There is a significant permanent deficit of Purkinje cells in the entire cerebellum with condensed alcohol exposure (in preparation). The $10.2 \%$ and $5.1 \%$ groups, with BACs in the order of $278 \pm 22$ (mean \pm sd) and $189 \pm 19 \mathrm{mg} / \mathrm{dl}$ had a $27 \%$ loss of Purkinje cells and an $18 \%$ loss of Purkinje cells respectively compared to the GC group. The group that had a continually elevated blood alcohol concentration with BACs between 20 to $34 \mathrm{mg} / \mathrm{dl}$, the $2.5 \%$ group, did not show a significant 
cell loss with a reduction in the total number of Purkinje cells of only $10 \%$ compared to the control animals.

Unpublished observations also show that in both the entire cerebellum and the hemisphere alone, the total number of Purkinje cells in both control and high BAC binge group does not differ between PN10 and PN115. This indicates that alcohol induced Purkinje cell death occurs during the period of alcohol exposure. It is important to remember that alcohol exposure spans a 6 day period of development and work by Goodlett and Lundahl (1996) using the optical fractionator has substantiated the finding that PN4-6 is a window of increased vulnerability to alcohol induced cell loss. Cell death may occur within this period (Hamre and West, 1993) allowing sufficient time before PN10 for cell loss to cease and cell number to stabilise. It also suggests that naturally occurring cell death in the cerebellar Purkinje cells does not occur to any significant extent after PN10. An unbiased estimate of total number also allows us to compare the response to postnatal alcohol exposure across strains. This is an important aspect in the validation of an animal model as it is a measure of the generality of the effects and strengthens the case that the animal model shows typical responses that may be the same as those occurring in the human population. If we look at the effect of high BAC binge alcohol exposure in Long Evans and Sprague Dawley rats we see the same pattern of Purkinje cell loss with the alcohol exposure (unpublished observations). A 28\% loss in both strains. As total number in the Sprague Dawley rats is $24 \%$ less than in the Long Evans, despite cerebellar weight being similar, a single section analysis may give quite different results.

In contrast to the entire cerebellum, the total number of Purkinje cells was significantly reduced in the FPF in all three alcohol treatment groups (see Table 3) (Napper and West, 1995). The 10.2\% group that received alcohol in the most condensed fashion showed a 34\% loss of Purkinje cells compared to $28 \%$ and $27 \%$ loss in the $5.1 \%$ and $2.5 \%$ groups. The extent of cell loss did not differ between the three groups. The number of granule cells was also significantly decreased with alcohol exposure in all of the treatment groups. The effect was more severe with the higher BACs, a loss of $27 \%$ and $31 \%$ compared to $24 \%$ in the low BAC group, but there was no statistically significant difference in granule cell number between the alcohol treatment groups. It is important to note that there was no significant change in either Vref or density for the granule cell population in the $2.5 \%$ alcohol treatment group, yet there was a permanent deficit in the total number of granule cells.

Preliminary data from lobule $\mathrm{X}$ has shown that the total number of Purkinje cells in the high BAC binge group of animals $(10.2 \%)$ is significantly less than in the gastrostomy control group (GC) (in preparation). There is a permanent loss of $43 \%$ of the Purkinje cells in this lobule. This compares with the $34 \%$ loss of Purkinje cells in the floccular parafloccular region and reinforces the vulnerability of early maturing Purkinje cells. This $43 \%$ loss compares with a loss of around $34 \%$ seen by Bonthius and West (1991b) in single section studies. There was no change in Purkinje cell density despite this huge cell loss, but a dramatic decrease in the volume of lobule $\mathrm{X}$.

Table 3. Reference Volumes, Purkinje Cell Densities and Total Number and Granule Cell Densities and Total Number in the Flocculus-Paraflocculus ${ }^{l}$.

\begin{tabular}{lclllll}
\hline $\begin{array}{l}\text { Treatment } \\
\text { group }\end{array}$ & $\mathrm{n}$ & Vref & $\begin{array}{l}\text { Purkinje cell } \\
\mathrm{N}\left(\mathrm{x} 10^{4}\right)\end{array}$ & $\begin{array}{l}\text { Purkinje cell } \\
\mathrm{Nv}\left(\mathrm{x} 10^{3} \mathrm{~mm}^{-2}\right)\end{array}$ & $\begin{array}{l}\text { Granule cell } \\
\mathrm{N}\left(\mathrm{x} 10^{7}\right)\end{array}$ & $\begin{array}{l}\text { Granule cell } \\
\mathrm{Nv}\left(\mathrm{x} 10^{9} \mathrm{~mm}^{-3}\right)\end{array}$ \\
\hline SC & 5 & $8.27 \pm 1.12$ & $3.05 \pm 0.38$ & $3.79 \pm 0.14$ & $1.60 \pm 0.15$ & $1.99 \pm 0.10$ \\
$\mathrm{GC}$ & 6 & $7.54 \pm 0.61$ & $3.18 \pm 2.33$ & $4.24 \pm 0.58$ & $1.64 \pm 0.19$ & $2.19 \pm 0.23$ \\
$2.5 \%$ & 6 & $7.22 \pm 0.58$ & $2.33 \pm 0.31^{* *}$ & $3.23 \pm 0.38^{* *}$ & $1.24 \pm 0.10^{*}$ & $1.69 \pm 0.12$ \\
$5.1 \%$ & 6 & $6.81 \pm 0.36$ & $2.30 \pm 0.18^{* *}$ & $3.37 \pm 0.17^{*}$ & $1.13 \pm 0.06 \dagger$ & $1.76 \pm 0.19^{*}$ \\
$10.2 \%$ & 6 & $6.47 \pm 0.67$ & $2.11 \pm 0.31^{* *}$ & $3.25 \pm 0.54^{* *}$ & $1.19 \pm 0.11 \dagger$ & $1.85 \pm 0.21^{*}$ \\
\hline
\end{tabular}

${ }^{1}$ All measures represent group means \pm one standard deviation

* Significantly different from gastrostomy control group $(p<0.05$, Scheffe test)

** Significantly different from gastrostomy control group $(p<0.01$, Scheffe test $)$

$\uparrow$ Significantly different from gastrostomy control group $(\mathrm{p}<0.001$, Scheffe test $)$ Modified from Napper and West, 1995. 
There is also a significant loss of Purkinje cells in the paramedian lobule of the cerebellum in the $10.2 \%$ group compared with the GC group (in preparation). The alcohol exposed animals have a $17 \%$ deficit in the total number of Purkinje cells as compared to the gastrostomy control animals. This lobular loss compares to a $29 \%$ loss of the Purkinje cells across the entire cerebellar hemispheres indicating that hemispheral lobules also show differential sensitivity to alcohol's neurotoxic effects.

Postnatal alcohol exposure from PN4 to PN10 in a binge manner (10.2\% group) also has an effect on the total number of neurons in both the deep cerebellar nuclear complex and the inferior olivary nuclei. There are $28 \%$ fewer neurons in the DCN of the alcohol exposed animals than in the gastrostomy control group. The magnitude of this loss is comparable to the $27 \%$ loss of Purkinje cell loss found in the entire cerebellum (in preparation). The inferior olive has a permanent neuronal deficit of $25 \%$ in the alcohol exposed animals compared to gastrostomy control animals (Napper and West, 1995). When we compare the loss of neurons in the inferior olive with the cerebellar Purkinje cell loss the ratio of Purkinje cells to inferior olivary neurons remains constant across the groups, despite significant cell loss in both populations.

High BAC binge alcohol exposure during the early postnatal period resulted in a permanent deficit in both Purkinje cell and granule cell number in the floccular parafloccular region of the cerebellum but the ratio of granule cells per Purkinje cell remained constant (Napper and West, 1995a). The number of parallel fibre synapses on an individual Purkinje neuron in the flocculus, training groups combined, was $9.32 \pm 2.1 \mathrm{x}$ 104 (mean \pm sem) for AE rats with $7.58 \pm 3.1 \times 104$ and $10.87 \pm 3.3 \times 104$ for GC and SC rats respectively (in preparation). The GC group had significantly less synapses on an individual Purkinje neuron than in the SC group. It appears that the constancy of granule cells in the FPF following alcohol exposure is paralleled by a constancy in the synaptic contacts between the two cell populations. This preliminary data requires further investigation as the variance within the groups is rather high and it is surprising that GC group shows a deficit in synaptic number per cell compared to the $\mathrm{SC}$ animals.

\section{THE IMPORTANCE OF TOTAL NUMBER}

Unbiased stereological methods have demonstrated that cell loss, following alcohol exposure from postnatal day 4 to 10 , occurs throughout the cerebellar network.
Use of these methods has also detected cell loss in a specific region of the cerebellar cortex, the flocculusparaflocculus, as a result of exposure to low, but continually elevated blood alcohol concentrations, a level of exposure that previously has been considered to not result in significant cell loss (Bonthius and West, 1991b; Napper and West, 1995). Preliminary studies of the cell loss in specific cerebellar lobules has substantiated earlier findings that there is considerable regional variation in the magnitude of cell loss but this cell loss, as indicated by data for vermal lobule $\mathrm{X}$ may be more severe than previous studies have suggested (Bonthius and West, 1991b). The differential vulnerability of cerebellar lobules to alcohol induced cell loss may be very important in understanding that functional deficits that do occur when cell loss across the entire cerebellum cannot be detected (Goodlett and Lundahl, 1996). The use of total number has also allowed the quantitative relationship between functionally related cell populations to be assessed as cell ratios. Interestingly, following alcohol induced cell loss, the cell to cell ratios remain constant at the levels seen in control animals despite the fact that cell loss is occurring when each individual cell population is at a different developmental stage. This leads me to suggest that there may be a single cell population in the cerebellar network that is particularly sensitive to the neurotoxic effect of alcohol and cell loss in this cell population leads to a cascade of cell loss in an attempt to maintain normal quantitative relationships within the cerebellar network. Alternatively a number of cell populations are vulnerable to alcohol induced cell death at very different developmental stages and altered cerebellar development following the period of cell death may be responsible for maintaining normal quantitative relationships within the cerebellum. The disector method is being used increasingly with specific labelling techniques to identify cells on a functional basis rather than morphological criteria (e.g. Janson and Moller, 1993; Petersen et al., 1996; 1999). Specific labelling of cells of the cerebellar cortex and disector based counting of these cell populations may be one way in which stereological methods will continue to contribute to our understanding of the consequences and process of cell loss subsequent to alcohol exposure during the early postnatal period.

The subject of this review paper was presented as a Keynote Address (Napper, 1999) at the $\mathrm{X}^{\text {th }}$ International Congress for Stereology, Melbourne, Australia, 1-4 November 1999. 


\section{ACKNOWLEDGEMENTS}

I thank Jo Mahony for raising the animals used in this study, Sarah Spencer, Kristel Aalders, James Jowsey and Mark Phillips for technical assistance and Dr Peter Herbison for help with statistical analysis. This work was supported by grants from the Dunedin School of Medical Sciences, N.Z. Lottery Grants Board and U.S. Public Health Service Grant AA 09838.

\section{REFERENCES}

Abel EL (1995). An Update on Incidence of FAS: FAS is not an Equal Opportunity Birth Defect. Neurotoxicol Teratol 17:437-43.

Abercrombie (1946). Estimation of nuclear population from microtome sections. Anat Rec 94:239-47.

Aika Y, Ren JQ, Kosaka K, Kosaka T (1994). Quantitative analysis of GABA-like-immunoreactive and parvalbumincontaining neurons in the CA1 region of the rat hippocampus using a stereological method, the disector. Exp Brain Res 99:267-76.

Bauer-Moffett C, Altman J (1977). The effect of ethanol chronically administered to preweanling rats on cerebellar development: A morphological study. Brain Res 119:24968.

Bonthius DJ, West JR (1990). Alcohol-induced neuronal loss in developing rats: Increased brain damage with binge exposure. Alcoholism: Clin Exp Res 14:107-18.

Bonthius DJ, West JR (1991a). Acute and long-term neuronal deficits in the rat olfactory bulb following alcohol exposure during the brain growth spurt. Neurotoxicol Teratol 13:611-9.

Bonthius DJ, West JR (1991b). Permanent neuronal deficits in rats exposed to alcohol during the brain growth spurt. Teratology 44:147-63.

Bonthius DJ, Bonthius NE, Napper RMA, West JR (1992). Early postnatal alcohol exposure acutely and permanently reduces the number of granule cells and mitral cells in the rat olfactory bulb: A stereological study. J Comp Neurol 324:557-66.

Braendgaard H, Gundersen HJG (1986). The impact of recent stereological advances on quantitative studies of the nervous system. J Neurosci Meth 18:39-78.

Chernoff GF (1977). The fetal alcohol sundrome in mice: An animal model. Teratology 15:223-9.

Coggeshall RE (1992). A consideration of neural counting methods. TINS 15:9-13.

Coggeshall RE, Lekan HA (1996). Methods for determining numbers of cells and synapses: a case for more uniform standards of review. J Comp Neurol 364:6-15.

Cruz-Orive L-M (1983). Distribution-free estimation of sphere size distributions from slabs showing over-projection and truncation, with a review of previous methods. J Microsc 131:265-90.
Geinisman H.J, Gundersen HJG, Zee EV, West MJ (1996). Unbiased stereological estimation of the total number of synapses in a brain region. J. Neurocytol 25:805-19.

Goodlett CR, Lundahl KR (1996). Temporal determinants of neonatal alcohol induced cerebellar damage and motor performance eficits. Pharmacol Biochem Behavior 55:531-40.

Gundersen HJG (1986). Stereology of arbitary particles: A review of unbiased number and size estimators and the presentation of some new ones, in memory of William $\mathrm{R}$ Thompson. J Microsc 143:3-45.

Gundersen HJG, Bendtsen TF, Korbo L, Marcussen N, Moller A, Nielsen K, Nyengaard JR, Pakkenberg B, Sorensen FB, Vesterby A, West MJ (1988). Some new, simple and efficient stereological methods and their use in pathological research and diagnosis. APMIS 96:379-94.

Hamre KM, West JR (1993). The effects of the timing of ethanol exposure during the brain growth spurt on the number of cerebellar Purkinje and granule cell nuclear profiles. Alcoholism Clin Exp Res 17:610-22.

Howard V, Reid S, Baddeley A, Boyde A (1985). Unbiased estimation of particle density in the tandem scanning reflected light microscope. J Microsc 138:203-12.

Ito M (1984). The Cerebellum and Neural Control. New York: Raven Press.

Janson AM, Moller A (1993). Chronic nicotine treatment counteracts nigral cell loss induced by a partial mesodiencephalic hemitransection: an analysis of the total number and mean volume of neurons and glia in substantia nigra of the male rat. Neurosci 57:931-41.

Kempermann H, Gage FH (1997). More hippocampal neurons in adult mice living in an enriched environment. Nature 386:493-5.

Klintsova AY, Cowell RM, Swain RA, Napper RM, Goodlett CR, Greenough WT (1998). Therapeutic effects of complex motor training on motor performance deficits induced by neonatal binge-like alcohol exposure in rats. I. Behavioral results. Brain Res 800:48-61.

Liley DTJ and Wright J (1994). Intracortical connectivity of pyramidal and stellate cells: estimates of synaptic densities and coupling symmetry. J Network: Comp Neural Systems 5:175-89.

Marcussen BL, Goodlett CR, Mahoney JC, West JR (1994). Developing rat Purkinje cells are more vulnerable to alcohol-induced depletion during differentiation than during neurogenesis. Alcohol 11:147-56.

Mayhew TM (1992). A review of recent advances in stereology for quantifying neural structure. J Neurobiol 21:313-28.

Mayhew TM, Gundersen HJG (1996). 'If you assume, you can make an ass out of u and me': a decade of the disector for stereological counting of particles in 3D space. J Anat 188:1-15.

Miller MW, Al-Ghoul WM (1993). Numbers of neurons in 
the developing principal sensory nucleus of the trigeminal nerve: Enhanced survival of early-generated neurons over late-generated neurons. J Comp Neurol 330:491-501.

Miller MW, Potempa G (1990). Numbers of neurons and glia in mature rat somatosensory cortex: Effects of prenatal exposure to ethanol. J Comp Neurol 293:92-102.

Mouton PR, Pakkenberg B, Gundersen HJG, Price DL (1994). Absolute number and size of pigmented locus coeruleus neurons in young and aged individuals. J Chem Neuroanat 7:185-90.

Napper RMA, West JR (1995). Permanent neuronal cell loss in the cerebellum of rats exposed to continuous low blood alcohol levels during the brain growth spurt: A stereological investigation. J Comp Neurol 362:283-92.

Navarro A, Gonzalez del Rey C, Tolivia J, Alvarez-Uria M (1996). Ultrastructural and quantitative study of atypical age-related bodies in the hamster brain. Mech Ageing Develop 90:75-90.

Oorschot DE (1994). Are you using neuronal densities, synaptic densities or neurochemical densities as your definitive data? There is a better way to go. Progress Neurobiol 44:233-47.

Pakkenberg B, Gundersen HJG (1988). Total number of neurons and glial cells in human brain nuclei estimated by the disector and the fractionator. J Microsc 150:1-20.

Pakkenberg B, Gundersen HJG (1997). Neocortical neuron number in humans: effect of sex and age. J Comp Neurol 384:312-20.

Peterson DA, Lucidi-Phillipi CA, Murphy DP, Ray J, Gage FH (1996). Fibroblast growth factor-2 protects entorhinal layer II glutaminergic neurons from axotomy-induced death. J Neurosci 16:886-98.

Peterson DA, Dickinson-Anson HA, Leppert JT, Lee K-F, Gage FH (1999). Central neuronal loss and behavioral impairment in mice lacking neurotrophin receptor $\mathrm{p} 75$. J Comp Neurol 404:1-20.

Sowell ER, Jernigan TL, Mattson SN, Riley EP, Sobel DF, Jones KL (1996). Abnormal development of the cerebellar vermis in children prenatally exposed to alcohol:
Size reduction in lobules I-V. Alcoholism Clin Exp Res 20:31-4.

Sterio DC (1984). The unbiased estimation of number and sizes of arbitrary particles using the disector. J Microsc 134:127-36.

Sulik KK, Lauder JM, Dehart DB (1984). Brain malformations in prenatal mice following acute maternal ethanol administration. Int J Dev Neurosci 2:203-14.

Swaab DF, Uylings HBM (1987). Density measures: Parameters to avoid. Neurobiol Aging 8:574-6.

Tolcos M, Rees S (1997). Chronic placental insufficiency in the fetal guinea pig affects neurochemical and neuroglial development but not neuronal numbers in the brainstem: A new method for combined stereology and immunohistochemistry. J Comp Neurol 379:99-112.

Weibel ER (1980). Stereological Methods. Theoretical Foundations, Vol 2, New York: Academic Press.

West JR (1987). Fetal alcohol-induced brain damage and the problem of determining temporal vulnerablility: A review. Alcohol Drug Res 7:423-41.

West JR, Hamre KM, Pierce DW (1984). Delay in brain growth induced by alcohol in artificially reared rat pups. Alcohol 1:213-22.

West MJ (1993). Regionally specific loss of neurons in the aging human hippocampus. Neurobiol Aging 14:287-93.

West MJ (1999). Stereological methods for estimating the total number of neurons and synapses: issues of precision and bias. TINS 22:51-61.

West MJ, Gundersen HJG (1990). Unbiased stereological estimation of the number of neurons in the human hippocampus. J Comp Neurol 296:1-22.

West MJ, Slomianka L, Gundersen HJG (1991). Unbiased stereological estimation of the total number of neurons in the subdivisions of the rat hippocampus using the optical fractionator. Anat Rec 231:482-97.

West MJ, Ostergaard K, Andreassen OA, Finsen B (1996). Estimation of the number of somatostatin neurons in the striatum: An in situ hybridization study using the optical fractionator method. J Comp Neurol 370:11-22. 